\title{
Phenolic Compounds of Red Wine Aglianico del Vulture Modulate the Functional Activity of Macrophages via Inhibition of $N F-\kappa B$ and the Citrate Pathway
}

\author{
Anna Santarsiero $\mathbb{D}^{1},{ }^{1}$ Paolo Convertini ${ }^{\mathbb{D}}{ }^{1}$ Antonio Vassallo ${ }^{1},{ }^{1}$ Valentina Santoro, ${ }^{2}$ \\ Simona Todisco $\mathbb{D},{ }^{1}$ Dominga Iacobazzi, ${ }^{3}$ Yvonne Fondufe-Mittendorf $\mathbb{D}$, \\ Giuseppe Martelli $\mathbb{D}^{1},{ }^{1}$ Marcos R. de Oliveira ${ }^{(D},{ }^{5}$ Rosangela Montanaro, ${ }^{1}$ \\ Vincenzo Brancaleone $\mathbb{D}^{1},{ }^{1}$ Johannes Stöckl $\mathbb{D}^{6}{ }^{6}$ and Vittoria Infantino ${ }^{1}{ }^{1}$ \\ ${ }^{1}$ Department of Science, University of Basilicata, Viale dell'Ateneo Lucano 10, 85100 Potenza, Italy \\ ${ }^{2}$ Department of Pharmacy, University of Salerno, Via Giovanni Paolo II 132, 84084 Salerno, Italy \\ ${ }^{3}$ Bristol Heart Institute, Bristol Medical School, University of Bristol, Bristol BS2 8HW, UK \\ ${ }^{4}$ Department of Molecular and Cellular Biochemistry, University of Kentucky, Lexington, KY 40536, USA \\ ${ }^{5}$ Departamento de Bioquímica Rua Ramiro Barcelos, Universidade Federal do Rio Grande do Sul (UFRGS), 2600 Anexo \\ Santa Cecília, Porto Alegre, RS, Brazil \\ ${ }^{6}$ Institute of Immunology, Center for Pathophysiology, Infectiology and Immunology, Medical University of Vienna, \\ 1090 Vienna, Austria
}

Correspondence should be addressed to Vittoria Infantino; vittoria.infantino@unibas.it

Received 25 February 2021; Revised 30 April 2021; Accepted 8 May 2021; Published 26 May 2021

Academic Editor: Cecile Jacovetti

Copyright (c) 2021 Anna Santarsiero et al. This is an open access article distributed under the Creative Commons Attribution License, which permits unrestricted use, distribution, and reproduction in any medium, provided the original work is properly cited.

\begin{abstract}
Phenolic compounds of red wine powder (RWP) extracted from the Italian red wine Aglianico del Vulture have been investigated for the potential immunomodulatory and anti-inflammatory capacity on human macrophages. These compounds reduce the secretion of IL- $1 \beta$, IL- 6 , and TNF- $\alpha$ proinflammatory cytokines and increase the release of IL-10 anti-inflammatory cytokine induced by lipopolysaccharide (LPS). In addition, RWP restores Annexin A1 levels, thus involving activation of proresolutive pathways. Noteworthy, RWP lowers NF- $\kappa$ B protein levels, promoter activity, and nuclear translocation. As a consequence of NF- $\kappa \mathrm{B}$ inhibition, reduced promoter activities of SLC25A1-encoding the mitochondrial citrate carrier (CIC) - and ATP citrate lyase (ACLY) metabolic genes have been observed. CIC, ACLY, and citrate are components of the citrate pathway: in LPSactivated macrophages, the mitochondrial citrate is exported by CIC into the cytosol where it is cleaved by ACLY in oxaloacetate and acetyl-CoA, precursors for ROS, $\mathrm{NO}$, and $\mathrm{PGE}_{2}$ inflammatory mediators. We identify the citrate pathway as a RWP target in carrying out its anti-inflammatory activity since RWP reduces CIC and ACLY protein levels, ACLY enzymatic activity, the cytosolic citrate concentration, and in turn ROS, $\mathrm{NO}, \mathrm{PGE}_{2}$, and histone acetylation levels. Overall findings suggest that RWP potentially restores macrophage homeostasis by suppressing inflammatory pathways and activating proresolutive processes.
\end{abstract}

\section{Introduction}

Immunomodulators are heterogeneous compounds capable to interact with the immune system to upregulate or downregulate specific biological aspects of the host response. For example, phenolic compounds scavenge free radicals, pre- vent lipid peroxidation, modulate inflammatory pathway, and block the secretion of proinflammatory cytokines [1]. Resveratrol counteracts the production of proinflammatory cytokines, while anthocyanidins downregulate the expression of cyclooxygenase 2 (COX2) in macrophages exposed to lipopolysaccharide (LPS) [2]. Interestingly, resveratrol is able to 
dampen inflammation and induce apoptosis in immune cells by triggering proresolutive mediator Annexin A1 (AnxA1) pathway $[3,4]$.

In addition, cyanidin-3-O-glucoside, petunidin-3-O-glucoside, and delphinidin-3-O-glucoside inhibit the master regulator of the immune function in mammalian cells, the transcription factor NF- $\kappa \mathrm{B}$, in a mitogen-activated protein kinase- (MAPK-) dependent manner [5, 6]. Certain anthocyanidins can suppress the generation of reactive oxygen species (ROS) [7, 8]. For example, cyanidin-3-O-glucoside has great oxygen radical absorbance capacity (ORAC) in vitro [9] and delphinidin is one of the most active scavenger against superoxide anion [10]. Compounds found in red wine can also upregulate the transcription factor of the expression of antioxidant and detoxifying enzymes in mammalian cells, improving the cytoprotection against several types of stress [10].

In inflammatory processes, metabolic changes occur to meet the new energetic demands of cells. The result is the production of metabolites, which both can act as immune signaling molecules and supply substrates necessary for the biosynthesis of proinflammatory mediators [11, 12]. Activated dendritic cells and macrophages switch rapidly from a resting to an activated state characterized by a different metabolic profile. In particular, LPS or classically activated macrophages-also known as M1 macrophages-have high rates of glycolysis and pentose phosphate pathway while the Krebs cycle is broken at two points and fatty acid oxidation and oxidative phosphorylation are downregulated [11, 12]. The two breakpoints of Krebs cycle are at succinate dehydrogenase and isocitrate dehydrogenase, with consequent withdrawals of succinate and citrate from the cycle. Most of the citrate is channelled into the citrate pathway, made of the mitochondrial transporter citrate carrier (CIC) and the enzyme ATP citrate lyase (ACLY) [13-16]. CIC exports citrate from the mitochondria in exchange for malate. In the cytosol, ACLY cleaves it into oxaloacetate (OAA) and acetyl-coenzyme A (acetyl-CoA). OAA is converted to malate by cytosolic malate dehydrogenase 1 (MDH1) and to pyruvate by malic enzyme 1 (ME1) with consequent production of nicotinamide adenine dinucleotide phosphate (NADPH). Of note, both NADPH oxidase and inducible nitric oxide synthase (iNOS) need NADPH for ROS and nitric oxide (NO) synthesis, respectively [13, 15]. Acetyl$\mathrm{CoA}$ is processed into malonyl-coenzyme A (malonyl-CoA) by acetyl-coA carboxylase (ACC). Malonyl-CoA is a substrate for cholesterol or fatty acid synthesis. Therefore, it could be used for the production of arachidonic acid, a precursor for prostaglandin $\mathrm{E}_{2}\left(\mathrm{PGE}_{2}\right)$, a key modulator of inflammation with a crucial role in inflammatory diseases $[13,15]$. Acetyl-CoA is also a substrate for protein and histone acetylation [17]. Moreover, citrate is implied in itaconate synthesis that modulates the production of different inflammatory mediators, acting as a negative regulator of inflammation [18]. The citrate pathway has a key role also in diseases such as Down syndrome and Behçet syndrome $[19,20]$.

The red wines have become popular in recent years due to their content of phenolic compounds with antioxidant activity as well as hypolipidemic and anti-inflammatory effects. Although different studies have been performed on the red wine compounds, most of them are aimed at investigating the chemical composition, the biodiversity, the genetic diversity, the pedigree reconstitution, and the general antioxidant properties. In this study, we investigated on the beneficial immunomodulatory effect of a powder rich in phenolic compounds from the red wine Aglianico del Vulture. It is one of the best Italian red wines that has never been studied. We have focused on the secretion of proinflammatory and anti-inflammatory cytokines, NF- $\kappa \mathrm{B}$ expression, the citrate pathway, and epigenetic modifications in LPS-activated human macrophages. Such studies will help to identify the targets for RWP and the development of potential therapeutics in the prevention and treatment of inflammatory chronic diseases.

\section{Material and Methods}

2.1. Wine Samples. Red wine (Vitis vinifera L., Aglianico cultivar) was provided by Cantine del Notaio (Rionero, Italy). Grapes were harvested in September 2018, samples were collected after grape pressing, and the wine fermentation was completed (no residual sugar was present into the wine). The samples were frozen and stored at $-20^{\circ} \mathrm{C}$ before freeze drying. The wine samples $(500 \mathrm{~mL})$ in a glass cylinder were connected to a freeze drying apparatus and freeze-dried under vacuum using a Stellar Millrock ST8S5-1 lyophilizer (Millrock Technology, Kingston, NY, USA).

2.2. LC-MS and LC-MS/MS Analyses. Part of whole and dealcoholized wine sample was dissolved in $100 \mu \mathrm{L}$ of $40 \%$ $\mathrm{MeOH}$ with $0.1 \%(v / v)$ formic acid at a concentration of $10 \mathrm{mg} / \mathrm{mL}$ and centrifuged (5 min, $13,000 \mathrm{rpm}$ ), and $1 \mu \mathrm{L}$ aliquots were injected in a UPLC-ESI-Qtrap system. Mass spectrometry-based analyses were carried out to evaluate the amount of specialized metabolites (delphinidin, cyanidin, and malvidin, all glucoside, caffeic and coumaric acids, resveratrol, and quercetin). Quali-quantitative analysis was carried out using an API6500 Q-Trap spectrometer (AB Sciex, Foster City, CA, USA) coupled with a Nexerax2 UHPLC apparatus (Shimadzu, Kyoto, Japan), working in both positive and negative MRM modes.

The instrumental parameters were optimized directly injecting solutions containing pure compounds. A Kinetex column (Phenomenex) (C18 $100 \AA$, $50 \mathrm{~mm} \times 2.6 \mu \mathrm{m} \times 2.1$ $\mathrm{mm}$ ) was adopted for chromatographic analyses, and compounds were separated using a linear gradient from $5 \%$ to $50 \%$ of acetonitrile (eluent B) and water containing $0.1 \%$ formic acid (eluent A) over 5 minutes followed by a faster gradient until to $95 \%$ of $\mathrm{B}$. The flow rate was $0.35 \mathrm{~mL} / \mathrm{min}$, and the injection volume was $1 \mu \mathrm{L}$. To perform accurate quantitative analyses, 8 points (in the range $0.010-10 \mu \mathrm{g} / \mathrm{mL}$ ) calibration curves were built for all the standard compounds. The mean values \pm standard deviation from at least three experiments were reported. All data were processed using Analyst software (ABSciex), and identification of compounds was based on retention times, accurate mass measurements, MS/MS data, exploration of specific spectral libraries and public 
repositories for MS-based metabolomic analysis [21], and comparison with data reported in the literature [7, 22-25].

2.3. Isolation of Human Monocytes from Whole Blood. Primary human monocytes were isolated from healthy donors after obtaining written informed consent. The study was performed in agreement with the Declaration of Helsinki and in accordance with the Committee on Human Research approved procedures. Venous blood was collected into K2 EDTA-coated BD vacutainer tubes (Becton, Dickinson and Company, Franklin Lakes, NJ, USA). Peripheral blood mononuclear cells (PBMCs) were separated by Histopaque1077 (Sigma-Aldrich, St Louis, MO) density gradient centrifugation: whole blood was mixed with Hanks' Balanced Salt solution (HBSS, Sigma-Aldrich) at a ratio of $1: 2(v / v)$, layered on the top of Histopaque-1077 (Sigma-Aldrich) and centrifuged at $1000 \mathrm{xg}$ for 15 minutes. The layer of mononuclear cells (PBMCs) at the interphase was recovered and washed twice in HBSS. PBMCs were incubated with CD14 antibody conjugated to magnetic beads $\left(\mathrm{MACS}^{\circledR}\right.$, Miltenyi Biotec $\mathrm{GmbH}$, Bergisch Gladbach, Germany) for 15 minutes at $4^{\circ} \mathrm{C}$. After washing, cells were loaded onto $\mathrm{MACS}^{\circledR}$ column (Miltenyi Biotec $\mathrm{GmbH}$ ) placed in a magnetic field, and CD14- positive $\left(\mathrm{CD} 14^{+}\right)$and $\mathrm{CD} 14$-negative $\left(\mathrm{CD} 14^{-}\right)$populations were divided. The $\mathrm{CD} 14^{+}$monocytes were differentiated to macrophages by using $100 \mathrm{ng} / \mathrm{mL}$ human M-CSF in Roswell Park Memorial Institute (RPMI) 1640 medium (Thermo Fisher Scientific, San Jose, CA, USA) supplemented with $10 \%$ fetal bovine serum, $2 \mathrm{mM} \mathrm{L}$-glutamine, $100 \mathrm{U} / \mathrm{mL}$ penicillin, and $100 \mu \mathrm{g} / \mathrm{mL}$ streptomycin at $37^{\circ} \mathrm{C}$ in a humidified atmosphere of $5 \% \mathrm{CO}_{2}$.

2.4. Cell Culture and Treatments. Human embryonic kidney 293 cells (HEK293, Sigma-Aldrich) were grown in Dulbecco's Modified Eagle Medium (DMEM, Thermo Fisher Scientific) supplemented with $10 \%$ fetal bovine serum, $2 \mathrm{mML}$ glutamine, $100 \mathrm{U} / \mathrm{mL}$ penicillin, and $100 \mu \mathrm{g} / \mathrm{mL}$ streptomycin in a humidified chamber with $5 \% \mathrm{CO}_{2}$ at $37^{\circ} \mathrm{C}$. To evaluate the immunomodulatory and anti-inflammatory properties of Aglianico del Vulture red wine, primary human monocytes and HEK293 cells were treated with RWP 20 or $200 \mu \mathrm{g} / \mathrm{mL}$ for 1 hour. Then, inflammation was induced by $1 \mu \mathrm{g} / \mathrm{mL}$ of lipopolysaccharide isolated and purified from $E$. coli strain EH100 (AdipoGen Life Sciences, Inc., San Diego, USA). Except for cytokines and $\mathrm{PGE}_{2}$ quantification, cells were washed twice with PBS at the end of LPS treatment before proceeding with subsequent analyses, as detailed further in the sections below.

2.5. Cell Count. CD $14^{+}$monocytes were seeded into a 96-well plate $\left(2 \times 10^{4}\right.$ cells/well $)$ and treated with a wide range of RWP concentrations: 2.5, 5, 10, 20, 50, 100, 200, 400, 800, 1600 , and $3200 \mu \mathrm{g} / \mathrm{mL}$. After 72 hours, cell count was carried out by using the automated handheld Scepter 2.0 Cell Counter (Merck Millipore, Switzerland).

2.6. Quantification of Cytokines. CD $14^{+}$monocytes $\left(5 \times 10^{5}\right.$ cells) were pretreated in 24-well plates with RWP 20 or $200 \mu \mathrm{g} / \mathrm{mL}$ for 1 hour and then stimulated with $1 \mu \mathrm{g} / \mathrm{mL}$ of LPS. Twenty-four hours later, cell-free supernatants were collected and assayed for the concentration of interleukins $1 \beta, 6$, and 10 (IL- $1 \beta$, IL-6, and IL-10) and tumor necrosis factor $\alpha$ (TNF- $\alpha)$ by Luminex100 System (R\&D Systems, Inc., Minneapolis, MN, USA) using specific matched-pair antibodies and recombinant cytokines as standards following the manufacturer's recommendations.

2.7. Western Blotting. Cellular pellet was resuspended in Laemmli buffer and boiled for 5 minutes at $100^{\circ} \mathrm{C}$. Thirty micrograms of proteins were subjected to SDS-PAGE and then electroblotted onto nitrocellulose membranes. The membranes were blocked for 1 hour in a tris-buffered saline (TBS) solution containing 5\% nonfat dry milk and $0.5 \%$ Tween 20 and then immunostained at $4^{\circ} \mathrm{C}$ overnight with anti-NF- $\kappa$ B/p65 (ab7970, Abcam, Cambridge, MA), antiCIC [26, 27], anti-ATP citrate lyase (ab157098, Abcam), anti-acetylated H3 (ab47915, Abcam), anti-total H3 (ab1791, Abcam), anti-AnxA1 (GTX101070, GeneTex), and anti-FPR2 or anti- $\beta$-actin (ab8227, Abcam) antibodies. Following 1-hour incubation with HRP Goat anti-Rabbit IgG secondary antibody (Santa Cruz Biotechnology, Santa Cruz, CA, USA), the immunoreactions were detected by using the horseradish peroxidase substrate WesternBright ${ }^{\mathrm{TM}}$ ECL (Advansta, Menlo Park, CA, USA) at Chemidoc ${ }^{\mathrm{TM}}$ XRS detection system equipped with Image Lab Software for image acquisition and densitometric analysis (Bio-Rad Laboratories, Hercules, CA, USA).

2.8. Transient Transfection. For monitoring the activity of the $\mathrm{NF}-\kappa \mathrm{B}$ signaling pathway, HEK293 cells were transiently transfected with a NF- $\kappa \mathrm{B}$ reporter plasmid containing a firefly luciferase gene driven by five copies of $N F-\kappa B$ response element $\left(5^{\prime}\right.$-GGGACTTTCC- $\left.3^{\prime}\right)$ located upstream of the minimal TATA box promoter (pGL3-5xNF- $\kappa \mathrm{B}$ ). To measure SLC25A1 gene promoter activity, HEK293 cells were transfected as previously described [28] using pGL3 basicLUC vector (Promega, Madison, WI, USA) containing the $-1785 /-20 \mathrm{bp}$ region of the SLC25A1 gene promoter (SLC25A1pGL3) upstream of the luciferase reporter gene [29]. For ACLY gene promoter activity, in pGL3, basicLUC vector was cloned the $-3116 /-20 \mathrm{bp}$ region of the ACLY gene promoter (called "3000") or a deletion fragment of this region (called "1000") [30]. To normalize the extent of transfection, cells were transfected with $10 \mathrm{ng}$ of pRL-CMV (Promega). Twenty-four hours after transfection, HEK293 cells were triggered with LPS in the presence or absence of RWP 20 or $200 \mu \mathrm{g} / \mathrm{mL}$. The day after, cells were lysed and assayed for LUC activity by using the Dual-Luciferase ${ }^{\circledR}$ Reporter Assay System (Promega), according to the manufacturer's protocol.

2.9. Immunocytochemistry. Cells were induced with LPS for 1 or 3 hours in the presence or not of RWP 20 or $200 \mu \mathrm{g} / \mathrm{mL}$, then were washed in PBS and fixed by cross-linking with $3 \%$ paraformaldehyde solution. Following permeabilization with $\mathrm{PBS}+0.25 \%$ Triton $\mathrm{X}-100$ (PBST) and blocking with PBST $+1 \%$ BSA (bovine serum albumin), cells were incubated with anti-NF- $\kappa \mathrm{B} / \mathrm{p} 65$ (ab7970, Abcam) primary antibody at $4^{\circ} \mathrm{C}$ overnight. The day after, Alexa Fluor 488 
(Thermo Fisher Scientific) was used as a secondary antibody while Fluoroshield Mounting Medium with DAPI (ab104139, Abcam) was employed to preserve fluorescence and as a counterstain for DNA. The images were obtained with a fluorescence microscope (EVOS FLoid Cell Imaging Station, Thermo Fisher Scientific).

2.10. Quantification of Citrate. The amount of citrate was quantified in macrophages treated with LPS in the presence or not of RWP 20 or $200 \mu \mathrm{g} / \mathrm{mL}$ by a fluorometric method using the Citrate Colorimetric/Fluorometric Assay Kit (BioVision, Milpitas, CA, USA) as per the manufacturer's instructions.

2.11. ACLY Activity. Primary monocytes were pretreated with RWP 20 or $200 \mu \mathrm{g} / \mathrm{mL}$ for 1 hour and then activated to macrophages with LPS. At the end of treatments, cells were washed twice in ice-cold PBS. The cell pellet was resuspended in ice-cold $0.1 \%$ NP40 in PBS, and three freeze-melt cycles $\left(-80^{\circ} \mathrm{C}\right.$ for 8 minutes $/ 40^{\circ} \mathrm{C}$ for 4 minutes) were performed. After centrifugation, supernatant was collected and protein concentration was determined by Bradford assay. ACLY activity was assessed by the coupled malic dehydrogenase method [31, 32], as previously described [30]. The specific ACLY activity was expressed as a percentage of the control after normalization to the protein concentration.

2.12. ROS, NO, and $P G E_{2}$ Detection. To evaluate ROS and NO levels, $\mathrm{CD}^{\circ} 4^{+}$monocytes were triggered by LPS in the presence or not of RWP 20 or $200 \mu \mathrm{g} / \mathrm{mL}$. Where indicated, cells were treated also with $5 \mathrm{mM}$ sodium malate (SigmaAldrich) or $500 \mu \mathrm{M}$ NADPH (Sigma-Aldrich). Following 24 hours, ROS and $\mathrm{NO}^{\circ}$ concentrations were measured by using 6-Carboxy-2', $7^{\prime}$-Dichlorodihydrofluorescein Diacetate (DCF-DA, Thermo Fisher Scientific) and 4-Amino-5Methylamino-2', $7^{\prime}$-Difluorofluorescein Diacetate (DAFFM Diacetate, Thermo Fisher Scientific), respectively, as previously reported [33].

For $\mathrm{PGE}_{2}$ quantification, cells were exposed to RWP 20 or $200 \mu \mathrm{g} / \mathrm{mL}$ for 1 hour and, where indicated, cotreated with $5 \mathrm{mM}$ sodium acetate (Sigma-Aldrich); then inflammation was induced by LPS. At the end of 48 hours LPS treatment; $\mathrm{PGE}_{2}$ was measured by using Detect $\mathrm{X}^{\circledR}$ Prostaglandin E2 High Sensitivity Immunoassay Kit (Arbor Assays, Ann Arbor, MI, USA) as previously described [33].

2.13. Statistical Analysis. Results are shown as the means \pm $\mathrm{SD}$ of, at least, three independent experiments. Statistical significance of differences was determined by using one-way ANOVA followed by Dunnett's or Tukey's tests for multiple comparisons. The statistical methods used for each experiment are detailed in figure legends. Asterisks in figures denote statistical significance: ${ }^{*} p<0.05,{ }^{* *} p<0.01$, and ${ }^{* * *}$ $p<0.001$. When Tukey's post hoc test was performed, different letters indicate significant differences between treatments at $p<0.05$.

\section{Results}

3.1. Composition and Identification of the Red Wine Powder Components. The red wine powder from Aglianico del Vulture was freeze-dried under vacuum. Quali-quantitative analysis of RWP was performed by LC-ESI-QTrap-MS/MS and LC-ESI-QTrap-MS analyses. The use of the Kinetex column and LC-ESI-MS/MS (alternating positive and negative ionization modes) allowed for the simultaneous separation and identification of all compounds. Compounds identified showed very good results in the optimized chromatographic column with retention times that ranged from 1.21 to $2.51 \mathrm{~min}$. Extracted ion chromatograms for each compound are presented in Figure S1. Individual components were identified by comparison of their $\mathrm{m} / \mathrm{z}$ values in the total ion current (TIC) profile with those of the selected compounds described in the literature. In particular, seven compounds were identified in RWP (Table 1) belonging to a wide variety of structurally different metabolic classes: phenolic acids (caffeic acid and p-coumaric acid); stilbenes (resveratrol); anthocyanidins (delphinidin-3-O-glucoside, cyanidin-3-O-glucoside, and malvidin 3-O-glucoside); and flavonols (quercetin).

The tested Aglianico del Vulture red wine powder contained significant amounts of anthocyanidins. In particular malvidin-3-O-glucoside was the most abundant $(14.00 \pm 0.23 \mathrm{mg} / 100 \mathrm{~mL})$, followed by cyanidin-3-O-glucoside $(1.30 \pm 0.218 \mathrm{mg} / 100 \mathrm{~mL})$ and delphinidin-3-O-glucoside $(0.072 \pm 0.003 \mathrm{mg} / 100 \mathrm{~mL})$ (Table 1$)$. Our results are in accordance with the typical anthocyanin profiling of Aglianico wine, in which malvidin 3-O-glucoside represents about $60 \%$ of total anthocyanidins while contents of cyanidin-3-Oglucoside and delphinidin-3-O-glucoside are very low (around 5\%) [34]. The content of resveratrol in Aglianico del Vulture was $0.053 \pm 0.01 \mathrm{mg} / 100 \mathrm{~mL}$, similar to other Italian red wines $[26,35,36]$. Concentrations of caffeic acid and $p$-coumaric acid were $0.218 \pm 0.047 \mathrm{mg} / 100 \mathrm{~mL}$ and $0.078 \pm 0.002 \mathrm{mg} / 100 \mathrm{~mL}$, respectively. Quercetin was determined equal to $0.785 \pm 0.02 \mathrm{mg} / 100 \mathrm{~mL}$ as listed on Table 1 .

3.2. Evaluation of RWP Toxicity on Primary Human Monocytes. We next investigated the RWP toxicity. Primary human monocytes, isolated from peripheral blood of healthy donors, were treated with increasing concentrations of RWP, ranging from 2.5 to $3200 \mu \mathrm{g} / \mathrm{mL}$. After 72 hours, cell counts were performed. As shown in Figure 1, RWP did not affect the cell number until at a dose of $800 \mu \mathrm{g} / \mathrm{mL}$. A slight cytotoxicity was observed at the highest tested concentrations of 1600 and $3200 \mu \mathrm{g} / \mathrm{mL}$, where reductions in the cell number compared with untreated cells (0) were about 20\% and $40 \%$, respectively $\left({ }^{* * *} p<0.001\right.$, Dunnett's multiple comparisons test).

3.3. Effect of RWP on the Secretion of $I L-1 \beta, I L-6, T N F-\alpha$, and IL-10 Cytokines. To begin to understand the impact of this RWP on the human body, we analyzed its pro- and antiinflammatory properties. We treated primary human monocytes with LPS, a component of the outer membrane of Gram-negative bacteria that induces inflammatory cascade 
TABLE 1: Composition of the red wine powder (RWP) obtained from Aglianico del Vulture (harvest 2018). Mass spectrometrybased analyses were carried out to evaluate the amount of specialized metabolites in RWP. The mean values \pm standard deviation (SD) from at least three independent experiments, each in triplicate, are reported.

\begin{tabular}{lc}
\hline & $\mathrm{mg} / 100 \mathrm{~mL} \pm \mathrm{SD}$ \\
\hline Phenolic acids & $0.218 \pm 0.047$ \\
Caffeic acid & $0.078 \pm 0.002$ \\
Coumaric acid & \\
Stilbenes & $0.053 \pm 0.01$ \\
Resveratrol & \\
Anthocyanidins & $0.072 \pm 0.003$ \\
Delphinidin-3-O-glucoside & $1.30 \pm 0.18$ \\
Cyanidin-3-O-glucoside & $14.00 \pm 0.23$ \\
Malvidin-3-O-glucoside & \\
Flavonols & $0.785 \pm 0.02$ \\
Quercetin & \\
\hline
\end{tabular}

through the toll-like receptor 4 (TLR4) [27]. LPS leads to the rapid activation of proinflammatory cytokines IL- $1 \beta$, IL- 6 , and TNF- $\alpha$ [37] and the production of IL-10, a potent antiinflammatory cytokine.

We therefore assessed the release of IL- $1 \beta$, IL- 6 , TNF- $\alpha$, and IL-10 cytokines after 24 hours of stimulation of monocytes with LPS in the presence or absence of RWP. We observed marked and significant increases in the levels of all the cytokines analyzed after the induction with LPS (Figures 2(a)-2(d): unstimulated cells vs. LPS, $p<0.001$, Tukey's test). RWP lowered IL-1 $\beta$, IL-6, and TNF- $\alpha$ secretion in a dose-dependent manner (Figures 2(a)-2(c)). Specifically, at a dose of $200 \mu \mathrm{g} / \mathrm{mL}$, RWP reduced significantly by half the levels of all the proinflammatory cytokines released after stimulation with LPS, whereas RWP at a dose of $20 \mu \mathrm{g} / \mathrm{mL}$ decreased levels of IL-1 $\beta$, IL-6, and TNF- $\alpha$ (Figures 2(a)2(c): LPS vs. LPS + RWP $20 \mu \mathrm{g} / \mathrm{mL}, \mathrm{p}<0.001$, Tukey's test) by about $35 \%$. On the other hand, IL-10 levels increased significantly in a concentration-dependent manner when monocytes were treated with RWP compared to being triggered only with LPS (Figure 2(d): LPS vs. LPS + RWP $20 \mu \mathrm{g} / \mathrm{mL}-200 \mu \mathrm{g} / \mathrm{mL}, p<0.001$, Tukey's test).

3.4. Aglianico del Vulture Red Wine Powder Modulates Expression of Proresolutive Protein AnxA1 in Inflammatory Conditions. We next focused on the role of the AnxA1/FPR2 axis in LPS-induced inflammation in vitro. AnxA1 is a proresolutive protein induced and activated during inflammation, aimed at limiting tissue damage and restoring homeostasis through activation of Formyl Peptide Receptor 2 (FPR2) [3]. LPS treatment reduced total AnxA1 expression, while pretreatment with RWP, at both concentration used (20 or $200 \mu \mathrm{g} / \mathrm{mL}$ ), was able to restore its physiological amount, thus preventing cells to undergo excessive inflammation (Figure 3(a)). In addition, expression of FPR2 receptor was downregulated by LPS administration (Figure 3(b)).
Although not significantly, RWP slightly increased FPR2 expression, only causing a positive trend (Figure $3(\mathrm{~b})$ ).

3.5. Effect on Expression, Promoter Activity and Nuclear Translocation of NF- $\kappa B$. When LPS binds to TLR4 on the surface of macrophages, a signal transduction cascade leading to transcription of specific enzymes, such as COX2, matrix metalloproteinase-9, and inflammatory cytokines TNF- $\alpha$, IL-1, IL-6, IL-8, and chemokines [38]. The NF- $\kappa$ B pathway plays a central role for the protective properties of a moderate wine consumption [39]. Therefore, we evaluated if the red wine powder from Aglianico del Vulture will affect the NF$\kappa \mathrm{B}$ pathway. We focused on the expression of NF- $\kappa \mathrm{B}$, its promoter activity, and its cellular localization.

For this, primary human monocytes were treated with LPS in the presence or absence of RWP. LPS induced a marked overexpression of subunit p65 of NF- $\kappa \mathrm{B}$ (Figure 4(a)). RWP, used as both $20 \mu \mathrm{g} / \mathrm{mL}$ and $200 \mu \mathrm{g} / \mathrm{mL}$, reduced $\mathrm{p} 65 / \mathrm{NF}-\kappa \mathrm{B}$ protein levels to about $40 \%$ (Figure 4(a)). Likewise, even if significant (Tukey's test), no strong differences were found in the ability to inhibit NF$\kappa \mathrm{B}$ promoter activity between RWP $20 \mu \mathrm{g} / \mathrm{mL}$ and RWP $200 \mu \mathrm{g} / \mathrm{mL}$ (Figure 4(b)). To monitor the effect of RWP on the NF- $\kappa$ B signal transduction pathway, HEK293 cells were transiently transfected with a NF- $\kappa \mathrm{B}$ reporter plasmid containing a firefly luciferase gene driven by five copies of NF$\kappa \mathrm{B}$ response element located upstream of the minimal TATA box promoter. After activation by proinflammatory stimuli, endogenous NF- $\kappa \mathrm{B}$ binds to the DNA response elements, inducing transcription of the luciferase reporter gene. When cells were treated with LPS, we observed a significant increase in luciferase activity, when compared to untreated cells (Figure 4(b) C vs. LPS, $p<0.001$, Tukey's test); RWP reported the levels of luciferase activity in LPS-triggered cells at values similar to those of control. Next, we analyzed the cellular localization of $\mathrm{p} 65$, the subunit of NF- $\kappa \mathrm{B}$. After 1 hour (Figure $4(\mathrm{c})$ ) and 3 hours (Figure $4(\mathrm{~d})$ ) of treatment with LPS, we observed the translocation of subunit p 65 of NF- $\kappa \mathrm{B}$ from the cytosol to the nucleus. In cells cotreated with RWP, the main NF- $\kappa \mathrm{B}$ localization was cytosolic (Figures 4(c) and 4(d)). Altogether, these data suggest that RWP plays a role in inhibiting the NF- $\kappa$ B pathway.

3.6. Effect on the Citrate Export Pathway: Focus on CIC and Citrate. Among the proinflammatory genes activated by NF- $\kappa \mathrm{B}$ is SLC25A1, which encodes the mitochondrial citrate carrier (CIC). It is the component of the citrate pathway responsible for the export of the citrate withdrawn from the Krebs cycle to the cytosol after LPS stimulation [13, 14].

The human SLC25A1 promoter contains two NF- $\kappa \mathrm{B}$ response elements at positions $-414 /-405 \mathrm{bp}$ and $-1314 /-1305 \mathrm{bp}$. To verify if RWP induced alterations in the transcription rate of the SLC25A1 promoter, we transfected HEK293 cells with the previously described SLC25A1pGL3 - a vector with SLC25A1-promoter encompassing the $-1785 /-20$ bp region of the SLC25A1 gene cloned upstream of the luciferase reporter gene [29]. Next, we treated with LPS, in the presence or absence of RWP. We observed that RWP significantly reduced luciferase activity 


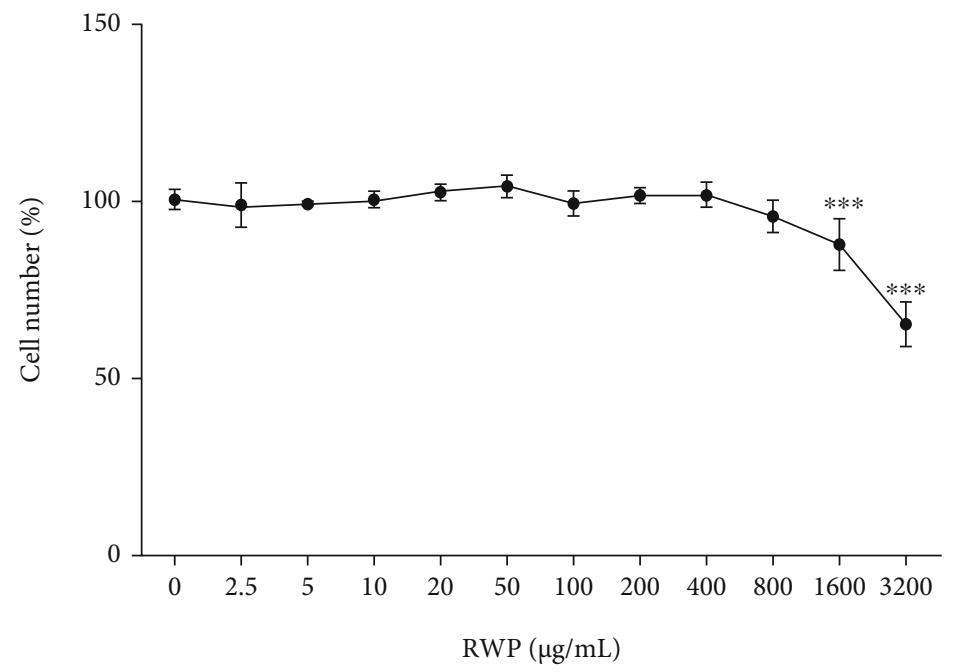

FIGURE 1: Effect of RWP on primary human monocyte cell number. Primary human monocytes were treated with increasing concentrations of RWP, ranging from 2.5 to $3200 \mu \mathrm{g} / \mathrm{mL}$, and cell viability was assessed by cell count after 72 -hour exposure. The mean values \pm SD of three independent experiments with four replicates in each are shown. Differences were significant $(p<0.001)$ according to one-way ANOVA. Dunnett's multiple comparisons test was run as post hoc test to compare treatment groups with the control group (0, set at $100 \%)$; where indicated, differences were statistically significant $\left({ }^{* * *} p<0.001\right)$.

in a dose-dependent manner by 50\% (RWP $20 \mu \mathrm{g} / \mathrm{mL}$ ) and $60 \%$ (RWP $200 \mu \mathrm{g} / \mathrm{mL}$ ) in cells upon LPS stimulation (Tukey's test, Figure 5(a)). We also measured the protein levels of CIC and confirmed a downregulation at the protein level (Figure 5(b)). However, we did not observe a dosedependent effect at the protein level. LPS induced a threefold overexpression of CIC with respect to untreated cells (Figure 5(b)), and RWP, as both $20 \mu \mathrm{g} / \mathrm{mL}$ and $200 \mu \mathrm{g} / \mathrm{mL}$, reported CIC levels to values similar to control cells (Figure 5(b)). A correspondent lowering in cytosolic citrate levels was detected: RWP either as $20 \mu \mathrm{g} / \mathrm{mL}$ or as $200 \mu \mathrm{g} / \mathrm{mL}$ reduced cytosolic citrate by around $40 \%$ with respect to LPStriggered cells (Figure 5(c)).

3.7. Effect on the Citrate Export Pathway: Focus on ATP Citrate Lyase. ACLY is upregulated very early in macrophages activated by LPS or by TNF- $\alpha$ and/or interferon $\gamma$ $(\operatorname{IFN} \gamma)$ as well as in inflammatory conditions $[15,19,20]$. To determine whether RWP affected NF- $\kappa$ B binding to ACLY, we analyzed the promoter region of the human ACLY gene. Since it contains an active NF- $\kappa \mathrm{B}$ response element localized at $-2048 /-2038$ bp [15], cells were transiently transfected with pGL3 basic-LUC vectors containing the $-3116 /-20 \mathrm{bp}$ full-length region of the ACLY gene promoter (called “3000," Figure 6(a)), including the NF- $\kappa$ B response element. As a control, we also transfected cells with a mutant version, containing a truncated version of this region (called "1000," Figure 6(a)), without the NF- $\kappa$ B response element. Both plasmids were then used to test the effect of RWP on luciferase activity. The absence of the binding site for NF$\kappa \mathrm{B}$ was responsible for the lower ACLY gene promoter activity in cells transfected with 1000 than 3000 (Figure 6(a)). Following 24 hours of LPS treatment, the strongest promoter activity was registered in 3000 transfected cells (3000 + LPS, Figure $6(\mathrm{a})$ ). The luciferase gene reporter activity was signif- icantly reduced to levels similar to unstimulated cells (3000, Figure 6(a)) by RWP $20 \mu \mathrm{g} / \mathrm{mL}$ and to even lower levels by RWP $200 \mu \mathrm{g} / \mathrm{mL}$ (Figure 6(a)). RWP induced a parallel decrease in ACLY protein levels and enzymatic activity in LPS-triggered macrophages (Figures 6(b) and 6(c)). More in detail, LPS induced a twofold increase in ACLY expression levels (Figure 6(b)) and a 35\% rise in ACLY activity (Figure 6(c)). No significant differences were observed between RWP $20 \mu \mathrm{g} / \mathrm{mL}$ and $200 \mu \mathrm{g} / \mathrm{mL}$ in bringing ACLY protein levels (Figure 6(b)) and activity (Figure 6(c)) down. These results, together with $\mathrm{CIC}$ and cytosolic citrate depletion, define a crucial role of RWP in immunometabolism.

Moreover, it has been recently demonstrated that rapid metabolic changes in LPS-induced macrophages are important to increase ACLY-derived acetyl-CoA that in turn leads to histone acetylation $[40,41]$, critical in regulating global chromatin accessibility and gene transcription. Transcriptional regulation of genes involved in macrophage activation and inactivation or determination of their polarization state occurs through histone modifications [42]. Therefore, changes in histone acetylation have a great impact in inflammation. We show that after LPS stimulation the levels of ACLY went up, with consequences in increased H3 histone acetylation (Figure 6(d)). On the other hand, treatment of cells with RWP lowered acetylated $\mathrm{H} 3$ in a dose-dependent manner (Figure 6(d)), suggesting an epigenetic activity of RWP.

3.8. Effect on the Levels of Inflammatory Mediators Downstream the Citrate Pathway: ROS and NO. Since RWP downregulated CIC and ACLY, we analyzed its role in regulating the citrate pathway in LPS-activated macrophages. Citrate cleavage made by ACLY supplies intermediaries for the biosynthesis of three inflammatory mediators: ROS, NO, and prostaglandin $\mathrm{E}_{2}$ [16]. In LPS-triggered 


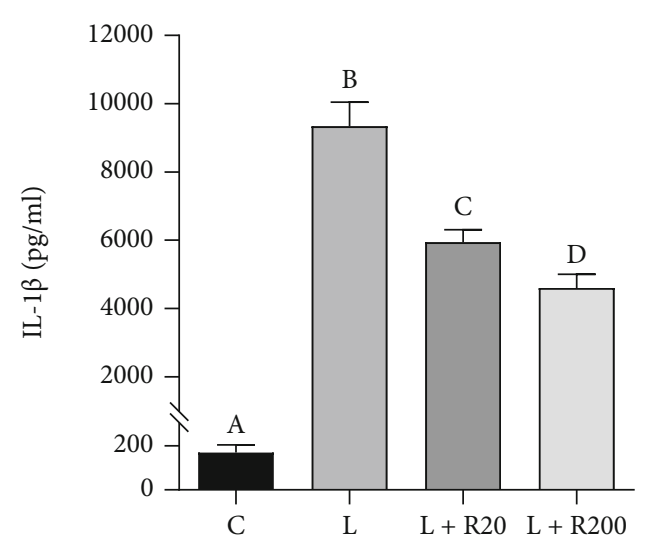

(a)

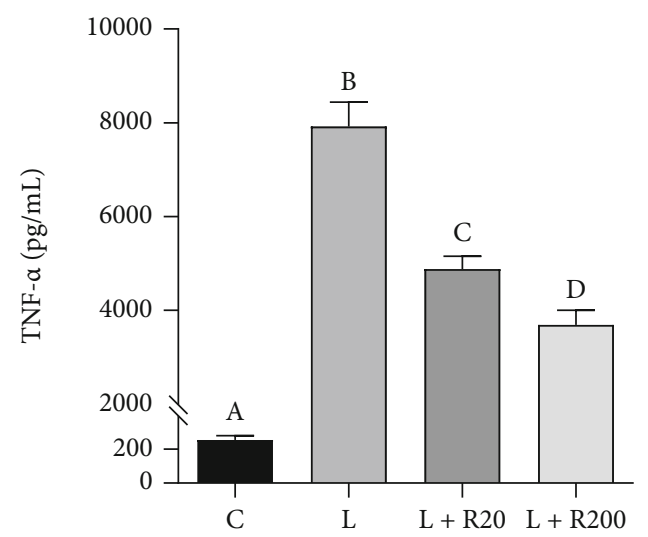

(c)

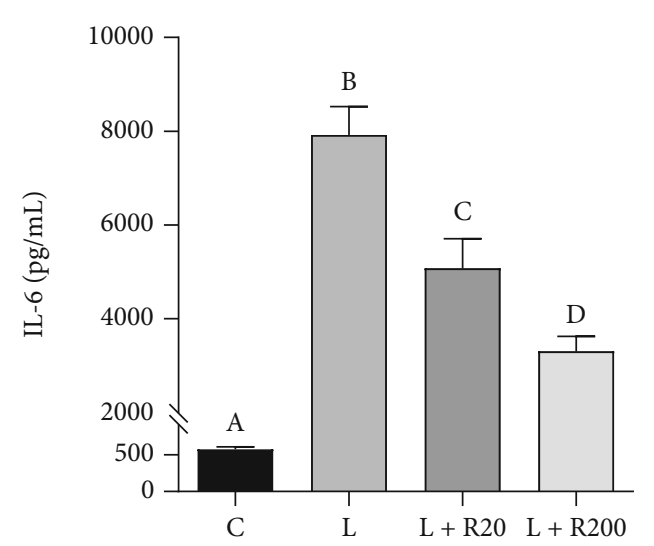

(b)

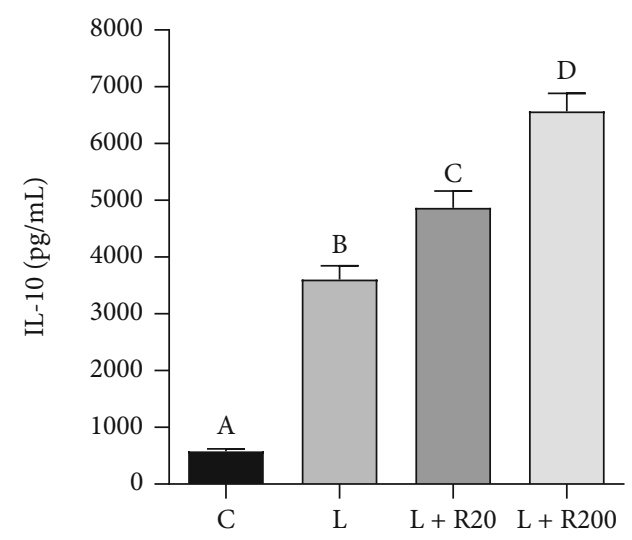

(d)

FIGURE 2: RWP affected the secretion of IL-1 $\beta$, IL-6, TNF- $\alpha$, and IL-10 cytokines. Primary human monocytes were incubated with RWP and activated to macrophages with $1 \mu \mathrm{g} / \mathrm{mL}$ LPS. Twenty-four hours later, the concentrations of the proinflammatory IL-1 $\beta$ (a), IL-6 (b), and TNF- $\alpha$ (c) and anti-inflammatory IL-10 (d) cytokines in cell culture supernatants were measured. Values represent the means \pm SD of three independent experiments with four replicates in each. According to one-way ANOVA, differences in IL-1 $\beta$ (a), IL-6 (b), TNF- $\alpha$ (c), and IL-10 (d) levels were significant $(p<0.001)$. Therefore, Tukey's post hoc test was performed, and different letters indicate significant differences between treatments at $p<0.05$. C: control; L: LPS; R20: RWP $20 \mu \mathrm{g} / \mathrm{mL}$; R200: RWP $200 \mu \mathrm{g} / \mathrm{mL}$.

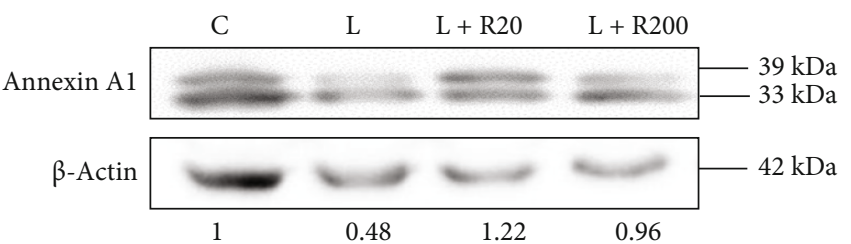

(a)

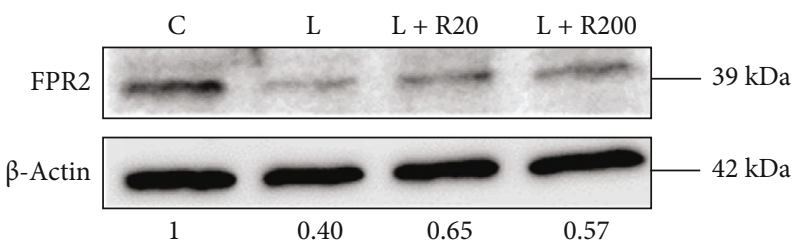

(b)

FIGURE 3: RWP significantly restored expression of AnxA1 in LPS-induced inflammation. Primary human monocytes were incubated with RWP $20 \mu \mathrm{g} / \mathrm{mL}$ or RWP $200 \mu \mathrm{g} / \mathrm{mL}$ and activated with $1 \mu \mathrm{g} / \mathrm{mL}$ LPS. Expression of AnxA1 (a) and FPR2 (b) was assessed following $24 \mathrm{~h}$ treatment with LPS. Protein expression was quantified by using optical density (O.D.) ratio for AnxA1 or FPR2 versus $\beta$-actin; normalized values obtained are reported under western blot images. C: control; L: LPS; R20: RWP $20 \mu \mathrm{g} / \mathrm{mL}$; R200: RWP $200 \mu \mathrm{g} / \mathrm{mL}$.

macrophages, the accumulated citrate is exported by CIC from the mitochondria to the cytosol and converted by ACLY into oxaloacetate and acetyl-CoA. OAA is converted to pyruvate with consequent production of NADPH [43], used for ROS and NO synthesis. Our analysis showed enhanced and significant releases of ROS and NO when human primary monocytes were treated with LPS (Figures 7(a) and 7(b)). RWP, on the other hand, reduced the levels of reactive oxygen species and nitric oxide in a dose-dependent manner (Figures $7(\mathrm{a})$ and $7(\mathrm{~b})$ ). In particular, RWP $20 \mu \mathrm{g} / \mathrm{mL}$ decreased by 10 and $15 \%$ the levels of ROS and NO, respectively, with respect to cells treated only with LPS; reductions induced by RWP $200 \mu \mathrm{g} / \mathrm{mL}$ were about 20 and $35 \%$ (Figures $7(\mathrm{a})$ and $7(\mathrm{~b})$ ).

Malate and NADPH are two metabolites downstream the citrate pathway: in particular, malate is produced in the 


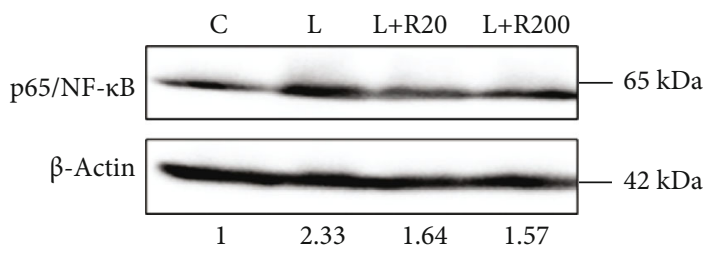

(a)

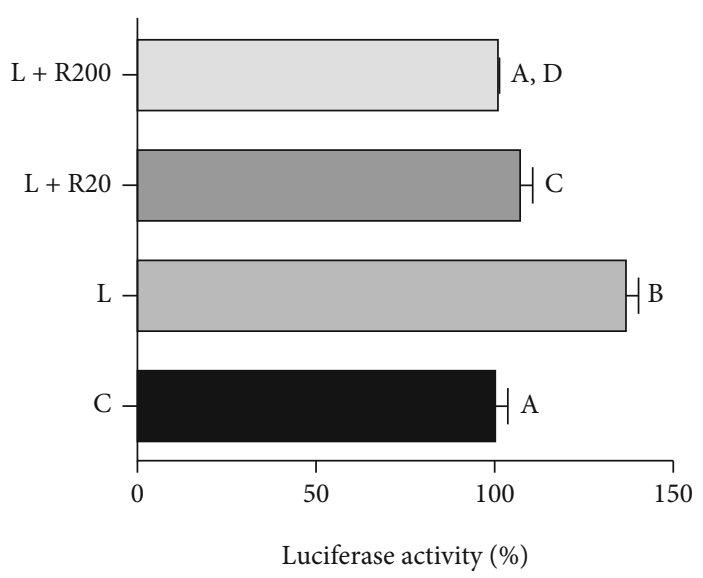

(b)

1 hour
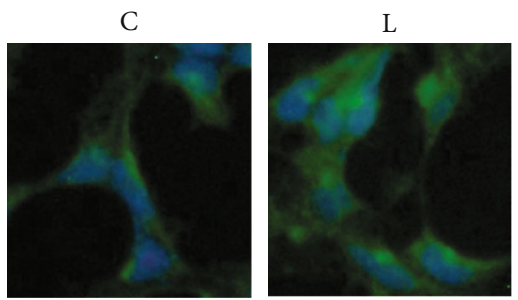

$\mathrm{L}+\mathrm{R} 20$

$\mathrm{L}+\mathrm{R} 200$
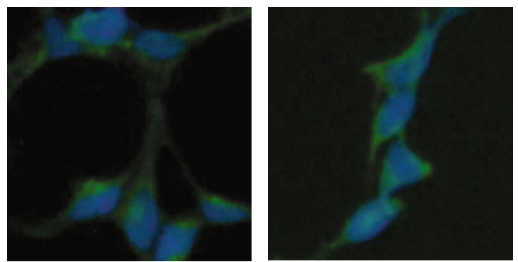

(c)

3 hours

C

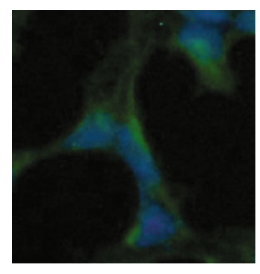

L

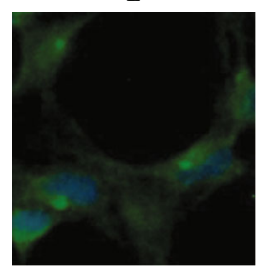

$\mathrm{L}+\mathrm{R} 20$

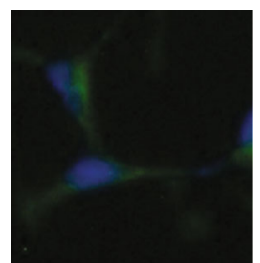

$\mathrm{L}+\mathrm{R} 200$

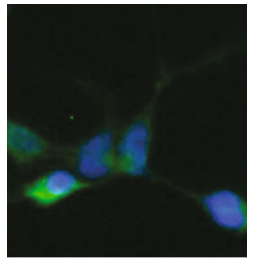

(d)

FIGURE 4: RWP inhibited NF- $\kappa$ B transcription factor. (a) Primary human monocytes were incubated with RWP $20 \mu \mathrm{g} / \mathrm{mL}$ or RWP $200 \mu \mathrm{g} / \mathrm{mL}$ and activated to macrophages with $1 \mu \mathrm{g} / \mathrm{mL}$ LPS. Specific antibodies detected the expression levels of subunit p65 of NF- $\kappa \mathrm{B}$ and $\beta$-actin. The intensities of immunolabeled protein bands were measured by a quantitative software and normalized to $\beta$-actin; values obtained are reported under western blot images. Protein expression levels in control sample were taken as 1, and other samples were expressed in proportion to the control. (b) HEK293 cells were transfected with NF- $\kappa$ B luciferase reporter plasmid and treated with LPS in the presence or not of RWP $20 \mu \mathrm{g} / \mathrm{mL}$ or RWP $200 \mu \mathrm{g} / \mathrm{mL}$. Bar chart reports the mean values \pm SD of three independent experiments, each in triplicate. According to one-way ANOVA, differences were significant $(p<0.001)$. Therefore, Tukey's post hoc test was performed, and different letters indicate significant differences between treatments at $p<0.05$. (c-d) Immunocytochemistry experiments were performed to identify the cellular localization of subunit p65 of NF- $\kappa \mathrm{B}$, recognized by a specific antibody. Cells were treated with RWP $20 \mu \mathrm{g} / \mathrm{mL}$ or RWP $200 \mu \mathrm{g} / \mathrm{mL}$ and activated with LPS. C: control; L: LPS; R20: RWP $20 \mu \mathrm{g} / \mathrm{mL}$; R200: RWP $200 \mu \mathrm{g} / \mathrm{mL}$.

reaction catalyzed by $\mathrm{MDH} 1$, while NADPH derived from the ME1 cleavage of malate in pyruvate. Exogenous malate used alone or in combination with NADPH reverts ACLY inhibition phenotype leading to a huge increase of both ROS and NO inflammatory mediators. As shown in Figures 6(a) and 6(b), the addition of malate alone or in combination with NADPH was sufficient to increase ROS as well as NO levels in LPS-triggered cells treated with RWP. Therefore, the effect of RWP on ROS and NO' levels could occur through the citrate pathway suppression together with a direct inhibition of NF- $\kappa \mathrm{B}$, which controls the expression of
ACLY, but also the expression of NADPH oxidase and iNOS genes $[44,45]$.

3.9. Inhibition of COX2 and Reduction of $P G E_{2}$ Level: Involvement of the Citrate Pathway. Finally, the focus was set on the other inflammatory mediator downstream the citrate pathway, $\mathrm{PGE}_{2}$, and on the enzyme $\mathrm{COX} 2$ responsible for its synthesis. It is well known that wine polyphenols inhibit COX2 in inflammation induced by LPS. Aglianico del Vulture red wine powder at $20 \mu \mathrm{g} / \mathrm{mL}$ as well as $200 \mu \mathrm{g} / \mathrm{mL}$ reduced COX2 expression levels almost the half 


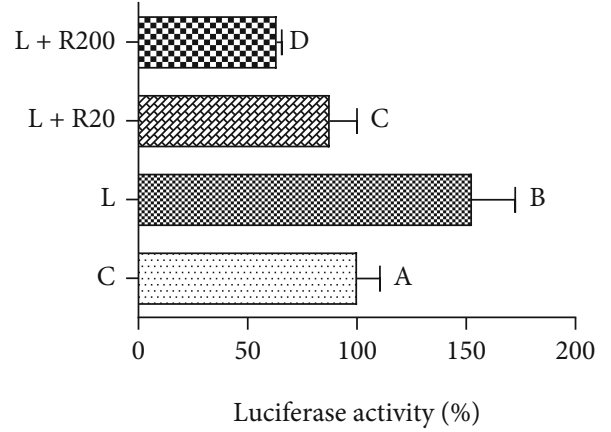

(a)

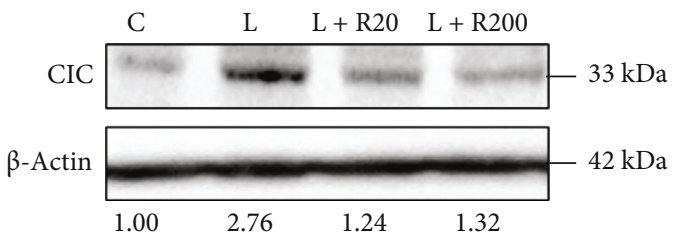

(b)

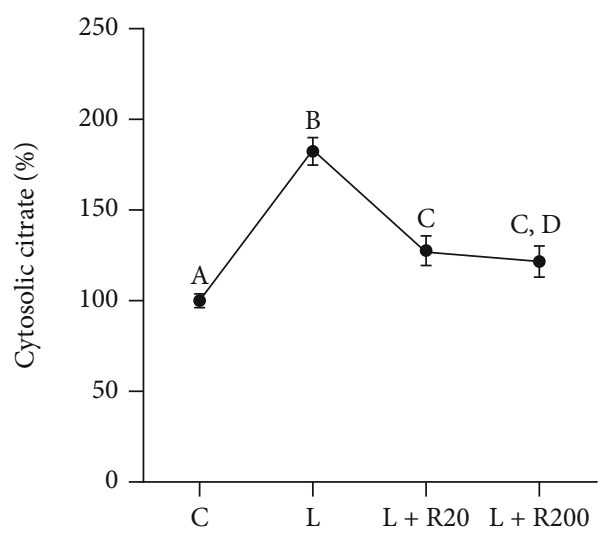

(c)

FIGURE 5: Effect of RWP on CIC and cytosolic citrate. (a) HEK293 cells were transiently transfected with SLC25A1pGL3, the pGL3 basic-LUC vector encompassing the $-1785 /-20$ bp region of the SLC25A1 gene cloned upstream of the luciferase reporter gene. Then, cells were triggered with LPS in the absence (LPS) or in the presence of RWP $20 \mu \mathrm{g} / \mathrm{mL}$ or RWP $200 \mu \mathrm{g} / \mathrm{mL}$. Unstimulated cells (c) were used as a negative control. The luciferase gene reporter activity was assessed after 24 hours. (b) Primary human monocytes, preincubated for 1 hour with RWP $20 \mu \mathrm{g} / \mathrm{mL}$ or RWP $200 \mu \mathrm{g} / \mathrm{mL}$, were activated to macrophages with LPS, and CIC protein levels were evaluated. CIC and $\beta$-actin proteins were immunodecorated with specific antibodies. The intensities of immunolabeled protein bands were measured by using a quantitative software and normalized to $\beta$-actin: values obtained are reported under western blot images. Protein expression levels in control sample were taken as 1 , and other samples were expressed in proportion of the control. (c) In cells treated as in (b), cytosolic citrate levels were quantified. In (a) and (c), values represent means \pm SD of three experiments with three replicates in each. Statistical analysis was performed by one-way ANOVA followed by Tukey's test for multiple comparisons. Different letters indicate significant differences at $p<$ 0.05. C: control; L: LPS; R20: RWP $20 \mu \mathrm{g} / \mathrm{mL}$; R200: RWP $200 \mu \mathrm{g} / \mathrm{mL}$.

with respect to macrophages activated only with LPS (Figure 8(a)). The strongest reduction was observed with the lowest tested concentration of RWP (Figure 8(a)). Interestingly, acetate, a metabolite downstream of the citrate pathway, reverted the inhibition of COX2 induced by RWP (Figure 8(b)). A similar trend was observed when $\mathrm{PGE}_{2}$ levels were measured in cell culture supernatants after 48 hours of incubation with LPS (Figure 8(c)). In details, RWPstimulated cells showed $\mathrm{PGE}_{2}$ levels similar to unstimulated cells. We observed a $40 \%$ decrease in $\mathrm{PGE}_{2}$ levels when compared to LPS-triggered cells. On the other hand, the addition of acetate brought $\mathrm{PGE}_{2}$ levels up (Figure $8(\mathrm{c})$ ). This decreased $\mathrm{PGE}_{2}$ level is most likely because of a decrease in $\mathrm{PGE}_{2}$ production, due to a reduced availability of precursors for $\mathrm{PGE}_{2}$ synthesis: as acetate can be converted to acetyl-CoA by acetyl-CoA synthase (ACSS), adding exogenous acetate rescues the effect of ACLY inhibition on $\mathrm{PGE}_{2}$ production. These data, with the previous regarding the effect of RWP on ROS and NO, strengthened and confirmed our hypothe- sis that the citrate pathway is a target of RWP in carrying out its anti-inflammatory activity.

\section{Discussion}

In this study, for the first time, we have investigated the biological properties of Aglianico del Vulture red wine and we have shown that it exerts potential health benefits thanks to its content in polyphenols well known to act as immunomodulators and anti-inflammatory molecules [1, $2,5,6,9,10,46-49]$.

Malvidin 3-O-glucoside and cyanidin-3-O-glucoside are the most abundant phenolic compounds we have found, in accordance with the typical anthocyanin profiling of Aglianico wine, in which malvidin 3-O-glucoside represents about $60 \%$ while cyanidin-3-O-glucoside and delphinidin-3-O-glucoside are around 5\% of total anthocyanidins [34]. These compounds were present in higher concentration with respect to another DOC red wine Carignano del Sulcis, 


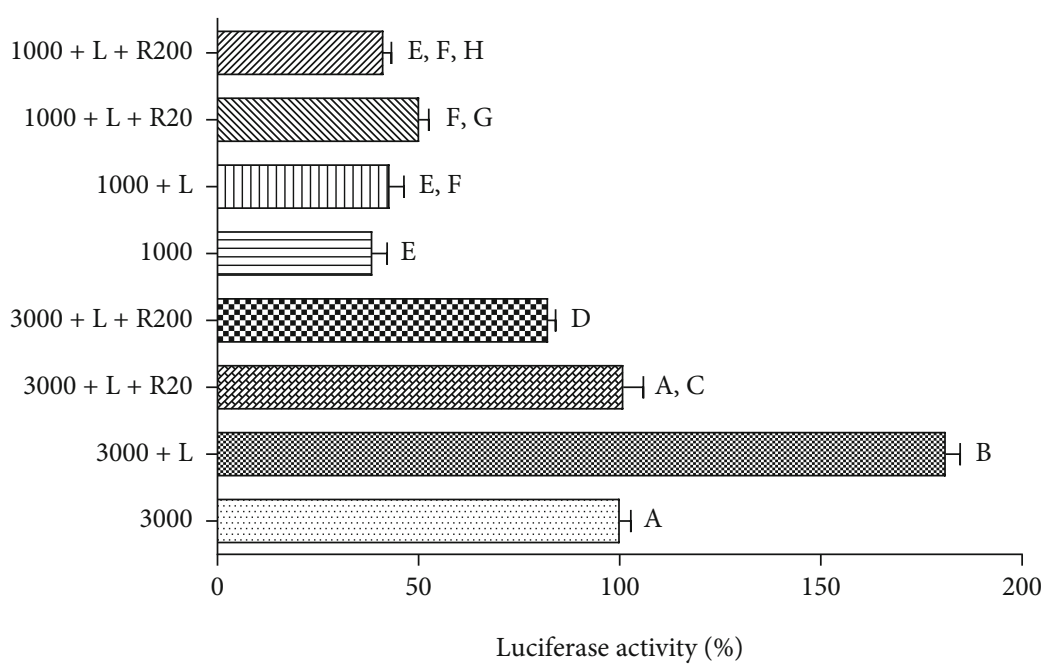

(a)

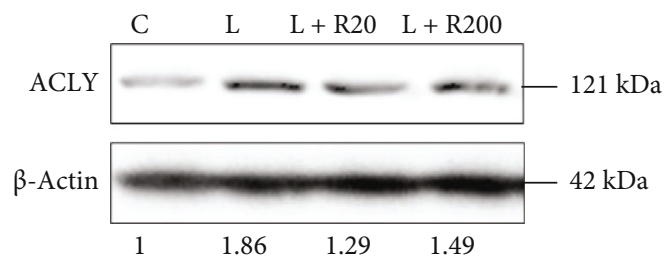

(b)

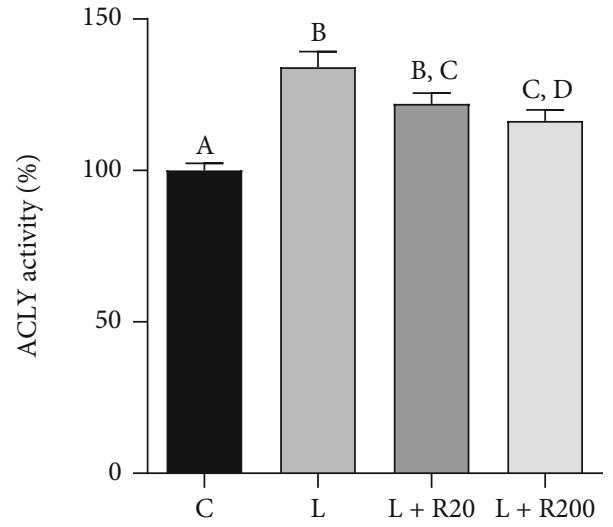

(c)

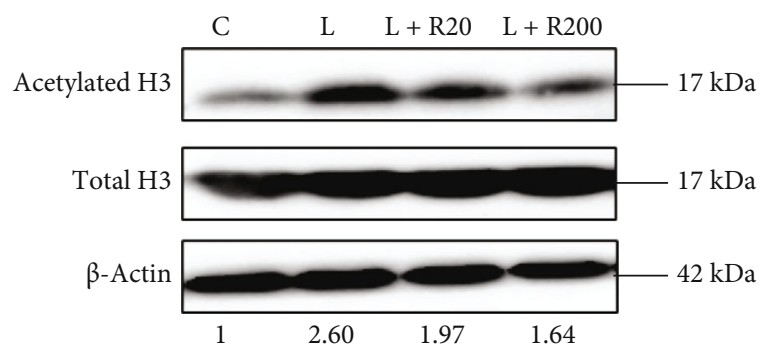

(d)

FIGURE 6: Effect of RWP on ACLY. (a) HEK293 cells were transiently transfected with pGL3 basic-LUC vectors containing the $-3116 /-20$ bp full-length region of the ACLY gene promoter (3000) or a truncated version of this region (1000). Then, cells were triggered with LPS in the absence (LPS) or in the presence of RWP $20 \mu \mathrm{g} / \mathrm{mL}$ or RWP $200 \mu \mathrm{g} / \mathrm{mL}$. Unstimulated cells were used as a negative control. The luciferase gene reporter activity was assessed after 24 hours. Primary human monocytes, preincubated for 1 hour with RWP, were activated to macrophages with LPS, and protein levels of ACLY (b) and acetylated H3 and total H3 (d) were evaluated. In (b, d) ACLY, acetylated H3, total $\mathrm{H} 3$, and $\beta$-actin proteins were immunodecorated with specific antibodies. The intensities of immunolabeled protein bands were measured by using a quantitative software and normalized to $\beta$-actin: values obtained are reported under western blot images. Protein expression levels in control sample were taken as 1, and other samples were expressed in the proportion of the control. (c) In cells treated as in (b, d) ACLY enzymatic activity was quantified. In (a) and (c), values represent means \pm SD of three experiments with three replicates in each. Statistical analysis was performed by one-way ANOVA followed by Tukey's test for multiple comparisons. Different letters indicate significant differences at $p<0.05$. C: control; L: LPS; R20: RWP $20 \mu \mathrm{g} / \mathrm{mL}$; R200: RWP $200 \mu \mathrm{g} / \mathrm{mL}$.

cultivated in the southwestern region of Sardinia (Italy) [24]. In our sample, the concentration of the stilbene resveratrol was lower $(0.053 \pm 0.01 \mathrm{mg} / 100 \mathrm{~mL})$ than that of red wines from Veneto region (Italy), in which resveratrol averaged $0.083 \mathrm{mg} / 100 \mathrm{~mL}$ [50], and Campania region (Italy) [26]. On the other hand, the flavonol quercetin was more abundant in Aglianico del Vulture red wine, compared to the last red wines from Campania, in particular with respect to Aglianico del Benevento [26]. Finally, among the phenolic acids, a higher rate of caffeic acid was found in our sample in comparison with wines counted among the best wines for antiinflammatory properties for their abundance in phenolic compounds, such as Cabernet Sauvignon, Merlot, Syrah, and Carménère [47].
Human primary monocytes have been used for our investigations. Cells were treated with LPS, which triggers innate immune responses leading to the secretion of cytokines IL- $1 \beta$, IL- 6 , and TNF- $\alpha$ and proinflammatory mediators blocked by Aglianico del Vulture powder. On the other hand, RWP induced an increased release of IL-10, necessary to initiate host defence against microbial invasion [37]. However, excessive secretion of proinflammatory cytokines could be deleterious for the host since they cause systemic metabolic and hemodynamic disturbances. For that reason, macrophages produce IL-10, a potent anti-inflammatory cytokine produced by macrophages as a negative-feedback mechanism to dampen excessive inflammation during infection. 


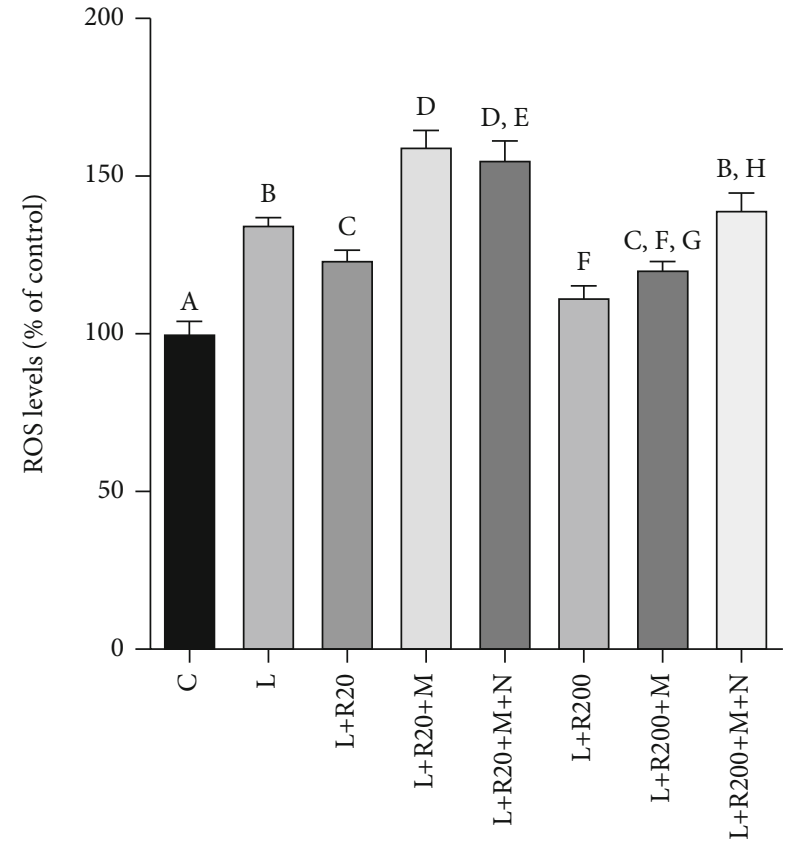

(a)

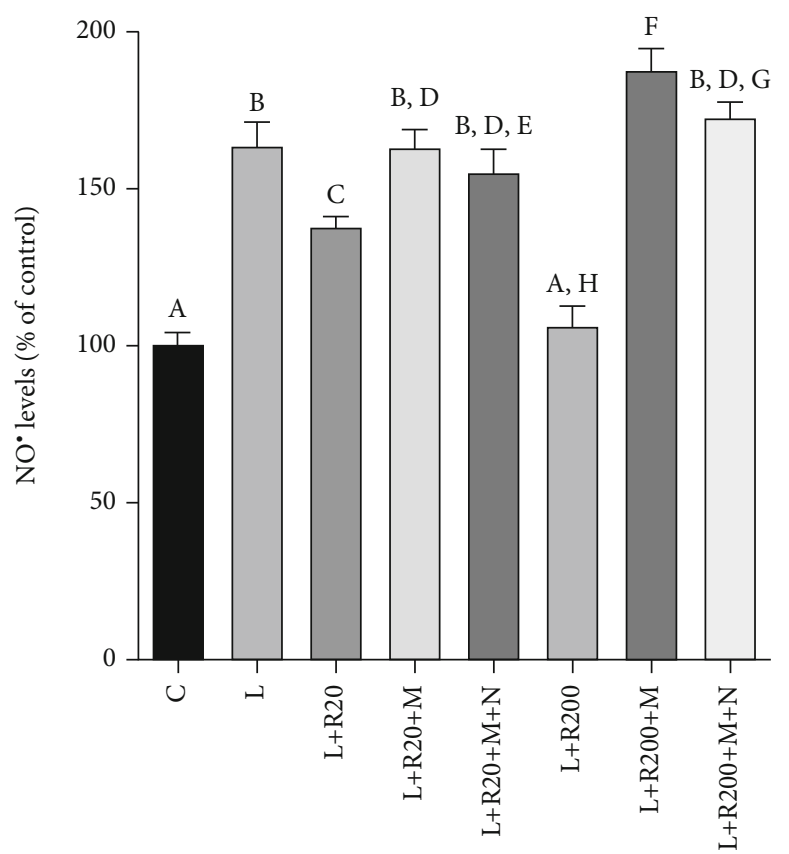

(b)

FIGURE 7: RWP lowered ROS and NO levels, restored by addition of exogenous malate and NADPH. Primary human monocytes were treated with LPS (L) in absence or in presence of RWP alone or plus malate and NADPH. Following 24 hours, ROS (a) and NO (b) levels were evaluated and expressed as the percentage of unstimulated cells (set at 100\%). Mean values \pm SD of three replicate independent experiments with five replicates in each are shown. According to one-way ANOVA, differences in ROS (a) and NO (b) levels were significant $(p<0.001)$. Therefore, Tukey's post hoc test was performed, and different letters indicate significant differences between treatments at $p<0.05$. C: control; L: LPS; R20: RWP $20 \mu \mathrm{g} / \mathrm{mL}$; R200: RWP $200 \mu \mathrm{g} / \mathrm{mL}$; M: malate; N: NADPH.

These data are in line with the rescuing effect exerted by RWP on AnxA1 levels, which were decreased upon LPS activation. This impairment could lead to uncontrolled inflammation resulting in chronic disease following unbalance between inflammation and resolution [51]. Thus, RWP could modulate inflammatory response with an alternate mechanism, which controls the resolution pathway associated to the AnxA1/FPR2 axis.

In vitro and in vivo studies reported that polyphenols contained in red grapes and red wines are able to abrogate the LPS-mediated activation of NF- $\kappa \mathrm{B}$ with consequent attenuation of the storm of proinflammatory cytokines released by monocytes [52], so that the NF- $\kappa \mathrm{B}$ pathway has been identified as a critical target for the protective properties of a moderate wine consumption. Therefore, our attention was directed to evaluate the effect of RWP on an NF- $\kappa \mathrm{B}$ transcription factor. As was to be expected, RWP reduced the expression of $\mathrm{p} 65$ subunit of NF- $\kappa \mathrm{B}$, promoter activity, and nuclear translocation of NF- $\kappa \mathrm{B}$. As a consequence of NF- $\kappa \mathrm{B}$ inhibition, SLC25A1 and ACLY gene promoter activities lowered with consequent reduction in CIC and ACLY protein levels; a parallel decrease in cytosolic citrate concentration and inflammatory mediators linked to the citrate pathway (ROS, NO; and $\mathrm{PGE}_{2}$ ) was observed. Obviously, the effect of the tested powder on ROS, NO, and $\mathrm{PGE}_{2}$ could also be a consequence of the direct inhibition of NF- $\kappa \mathrm{B}$ since under its transcriptional controls are genes encoding for iNOS and COX2. However, the inhibition of the citrate pathway has a central role. In fact, treatments with metabolites down- stream the citrate pathway removed RWP inhibitory effects on proinflammatory mediators: exogenous malate alone or in combination with $\mathrm{NADPH}$ reverted the reduction of ROS and NO levels; acetate did the same on $\mathrm{PGE}_{2}$ concentration and COX2 expression levels. Analogous involvement of the citrate pathway was found in Down syndrome, where hydroxycitrate-a natural ACLY inhibitor-reduced the typical prooxidant status, but the addition of malate or NADPH abolished its antioxidant effect [19]. Similarly, Pistacia lentiscus hydrosol exhibited its anti-inflammatory activity acting through the citrate pathway [30].

Interestingly, RWP exerts its effect also at the epigenetic level, as shown by reduction of the acetylation of $\mathrm{H} 3$ histone. Acetyl-CoA, a product of the citrate pathway needed for histone acetylation [17], represents a key node in metabolism due to its intersection with many metabolic pathways and transformations, influencing the regulation of numerous life processes.

In addition to the effect on the citrate pathway, it cannot be ruled out that the RWP compounds contained in this wine might have other beneficial effect. In fact, it is known that increasing of cytokines IL- $1 \beta$ and TNF- $\alpha$, with subsequent increased expression of adhesion molecules, contributes to lipid accumulation within the atheroma and dysregulated activity of vascular smooth muscle cells [53]. Thus, reduction of proinflammatory cytokines by RWP might also positively affect the cardiovascular system. Furthermore, since inflammation and ROS may induce the increase/decrease of several miRNAs, including oxidative stress-responsive miRNAs 


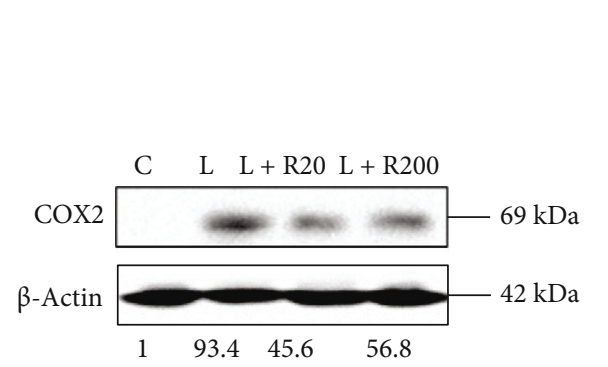

(a)

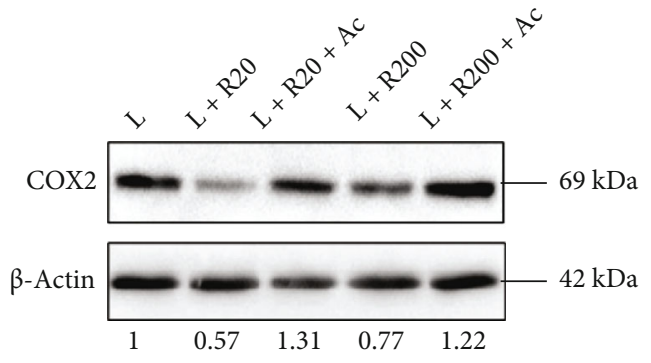

(b)

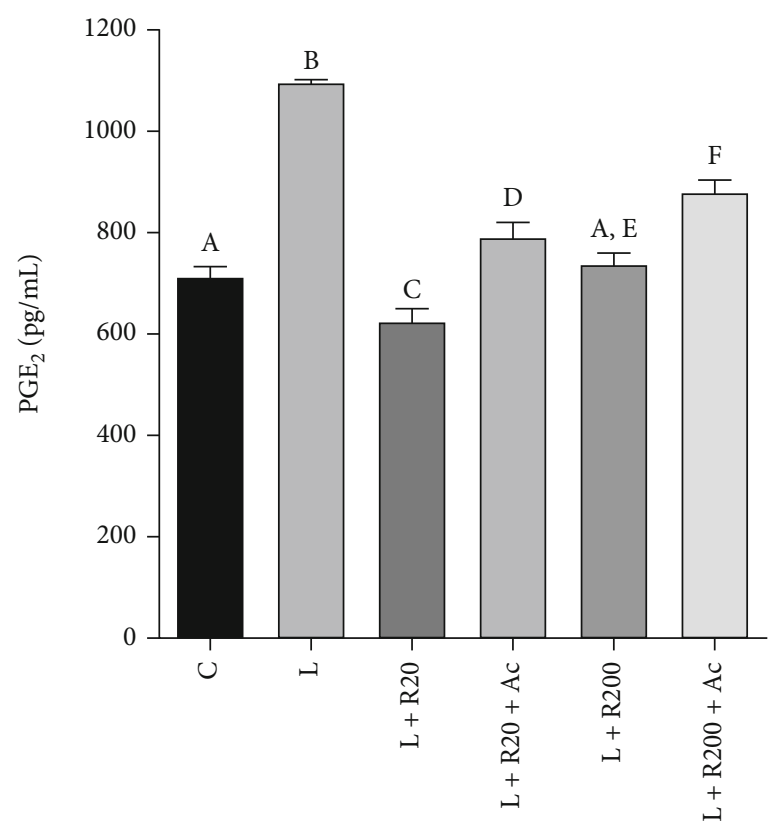

(c)

FIGURE 8: RWP lowered COX2 and PGE 2 levels. Primary human monocytes were activated to macrophages with LPS (LPS) in the absence or in the presence of RWP alone or plus acetate and $\operatorname{COX} 2(a, b)$, and $\mathrm{PGE}_{2}$ levels were quantified. In (a) and (b), COX2 and $\beta$-actin proteins were immunodecorated with specific antibodies. The intensities of immunolabeled protein bands were measured by using a quantitative software and normalized to $\beta$-actin; values obtained are reported under western blot images. Protein expression levels in control sample were taken as 1 , and other samples were expressed in proportion to the control. (c) Following 48 hours, PGE 2 levels were evaluated and expressed as the percentage of the levels in untreated cells (set at 100\%). Mean values \pm SD of three replicate independent experiments with three replicates in each are shown. According to one-way ANOVA, differences were significant $(p<0.001)$. Therefore, Tukey's post hoc test was performed, and different letters indicate significant differences between treatments at $p<0.05$. C: control; L: LPS; R20: RWP $20 \mu \mathrm{g} / \mathrm{mL}$; R200: RWP $200 \mu \mathrm{g} / \mathrm{mL}$; Ac: acetate.

[54], it could also be hypothesized that these phytochemicals may also control the expression of some target miRNAs in both normal and pathological conditions [55]. For example, the phytochemical epigallocatechin gallate may act as an epigenetic modulator of DNA methylation and chromatin remodeling, leading to the alteration of gene expression and modification of miRNA activities [56]. Other beneficial effects, such as glucose homeostasis, mitochondrial function, energy metabolism, and stress responses, have been ascribed to phenolic compounds [57]. However, further investigations are needed to elucidate these and other potential beneficial effects of RWP.

In conclusion, our study highlights for the first time the contribution of red wine Aglianico del Vulture phenols in modulation of inflammatory response. Notably, our findings suggest a specific signature of this red wine showing its own phenolic profile. The underlying mechanism is associated to different pathways, including the suppression of inflammatory mediators and the inhibition of NF- $\kappa \mathrm{B}$ and the citrate pathway. Bioactive compounds from red wines such as malvidin 3-O-glucoside and cyanidin-3-O-glucoside, quercetin and resveratrol, have been shown to inhibit inflammatory mediators via NF- $\kappa \mathrm{B}[46,48,49]$. The involvement of the citrate pathway is the strongest novelty, since this has never been investigated so far as a possible mechanism of action for any wine compounds. Here, we demonstrate that this pathway mediates several anti-inflammatory effects of the red wine Aglianico del Vulture phenols. In the recent years, the activation of ACLY and CIC-constituents of the citrate pathway-has been linked to the presence of inflammatory conditions [46, 48, 49]. Therefore, the citrate pathway seems a new hopeful target of inflammation. In this context, its 
inhibition by red wine Aglianico del Vulture phenols-as a molecular mechanism underlying the regulation of macrophage function-could reveal very interesting applications in the prevention and treatment of inflammatory chronic diseases simply through bioactive food compounds.

\section{Conclusions}

For the first time, this study investigates the immunomodulatory and anti-inflammatory potential of red wine powder (RWP) extracted from the Italian red wine Aglianico del Vulture. RWP reduces IL- $1 \beta$, IL- 6 , and TNF- $\alpha$ proinflammatory while increasing IL-10 anti-inflammatory cytokine secretion and inhibiting NF- $\kappa \mathrm{B}$ promoter activity in macrophages induced by LPS. In addition, RWP activates proresolutive pathways by restoring Annexin A1 levels. Beyond the classical targets of macrophage function, we also identify the citrate pathway as a RWP target in carrying out its antiinflammatory activity since, by reducing CIC and ACLY protein levels, ACLY enzymatic activity, RWP lowers ROS, NO, $\mathrm{PGE}_{2}$, and histone acetylation levels. Overall findings evidence that Aglianico del Vulture powder suppresses inflammatory pathways and activates proresolutive processes hinting the potential value of RWP in the prevention and treatment of inflammatory conditions as well as inflammatory chronic diseases.

\section{Data Availability}

The data used to support the findings of this study are available from the corresponding author upon request.

\section{Conflicts of Interest}

The authors declare no conflict of interest.

\section{Acknowledgments}

This research was supported by FSC European funds (grant number C31G19000020002) and Ministry of Education, University and Research (MIUR) PRIN (grant number 2017NKB2N4_004).

\section{Supplementary Materials}

Figure S1: MRM data in both positive and negative ions of a mix standard solution. (Supplementary Materials)

\section{References}

[1] N. Yahfoufi, N. Alsadi, M. Jambi, and C. Matar, "The immunomodulatory and anti-inflammatory role of polyphenols," Nutrients, vol. 10, no. 11, p. 1618, 2018.

[2] D. X. Hou, T. Yanagita, T. Uto, S. Masuzaki, and M. Fujii, "Anthocyanidins inhibit cyclooxygenase-2 expression in LPSevoked macrophages: structure-activity relationship and molecular mechanisms involved," Biochemical Pharmacology, vol. 70, no. 3, pp. 417-425, 2005.
[3] M. Perretti and F. D'Acquisto, "Annexin A1 and glucocorticoids as effectors of the resolution of inflammation," Nature Reviews. Immunology, vol. 9, no. 1, pp. 62-70, 2009.

[4] G. Li, S. He, L. Chang et al., "GADD45 $\alpha$ and annexin A1 are involved in the apoptosis of HL-60 induced by resveratrol," Phytomedicine, vol. 18, no. 8-9, pp. 704-709, 2011.

[5] J. W. Jeong, W. Lee, S. Shin, G. Y. Kim, B. Choi, and Y. Choi, "Anthocyanins downregulate lipopolysaccharide-induced inflammatory responses in BV2 microglial cells by suppressing the NF- $\kappa \mathrm{B}$ and Akt/MAPKs signaling pathways," International Journal of Molecular Sciences, vol. 14, no. 1, pp. 1502-1515, 2013.

[6] S. Vendrame and D. Klimis-Zacas, "Anti-inflammatory effect of anthocyanins via modulation of nuclear factor- B and mitogen-activated protein kinase signaling cascades," Nutrition Reviews, vol. 73, no. 6, pp. 348-358, 2015.

[7] C. Caddeo, A. Nacher, A. Vassallo et al., "Effect of quercetin and resveratrol co-incorporated in liposomes against inflammatory/oxidative response associated with skin cancer," International Journal of Pharmaceutics, vol. 513, no. 1-2, pp. 153163, 2016.

[8] T. Liang, R. Guan, Z. Quan, Q. Tao, Z. Liu, and Q. Hu, "Cyanidin-3-o-glucoside liposome: preparation via a green method and antioxidant activity in GES-1 cells," Food Research International, vol. 125, p. 108648, 2019.

[9] H. Wang, G. Cao, and R. L. Prior, "Oxygen radical absorbing capacity of anthocyanins," Journal of Agricultural and Food Chemistry, vol. 45, no. 2, pp. 304-309, 1997.

[10] T. Tsuda, K. Shiga, K. Ohshima, S. Kawakishi, and T. Osawa, "Inhibition of lipid peroxidation and the active oxygen radical scavenging effect of anthocyanin pigments isolated from Phaseolus vulgaris L," Biochemical Pharmacology, vol. 52, no. 7, pp. 1033-1039, 1996.

[11] L. A. J. O'Neill, R. J. Kishton, and J. Rathmell, "A guide to immunometabolism for immunologists," Nature Reviews. Immunology, vol. 16, no. 9, pp. 553-565, 2016.

[12] L. A. J. O’Neill and E. J. Pearce, “Immunometabolism governs dendritic cell and macrophage function," The Journal of Experimental Medicine, vol. 213, no. 1, pp. 15-23, 2016.

[13] V. Infantino, P. Convertini, L. Cucci et al., "The mitochondrial citrate carrier: a new player in inflammation," The Biochemical Journal, vol. 438, no. 3, pp. 433-436, 2011.

[14] V. Infantino, V. Iacobazzi, A. Menga, M. L. Avantaggiati, and F. Palmieri, "A key role of the mitochondrial citrate carrier (SLC25A1) in TNF $\alpha \backslash$ - and IFN $\gamma$-triggered inflammation," Biochimica et Biophysica Acta, vol. 1839, no. 11, pp. 12171225, 2014.

[15] V. Infantino, V. Iacobazzi, F. Palmieri, and A. Menga, "ATPcitrate lyase is essential for macrophage inflammatory response," Biochemical and Biophysical Research Communications, vol. 440, no. 1, pp. 105-111, 2013.

[16] V. Infantino, C. L. Pierri, and V. Iacobazzi, "Metabolic routes in inflammation: the citrate pathway and its potential as therapeutic target," Current Medicinal Chemistry, vol. 26, no. 40, pp. 7104-7116, 2019.

[17] L. Shi and B. P. Tu, "Acetyl-CoA and the regulation of metabolism: mechanisms and consequences," Current Opinion in Cell Biology, vol. 33, pp. 125-131, 2015.

[18] N. C. Williams and L. A. J. O’Neill, “A role for the Krebs cycle intermediate citrate in metabolic reprogramming in innate immunity and inflammation," Frontiers in Immunology, vol. 9, p. 141, 2018. 
[19] P. Convertini, A. Menga, G. Andria et al., "The contribution of the citrate pathway to oxidative stress in Down syndrome," Immunology, vol. 149, no. 4, pp. 423-431, 2016.

[20] A. Santarsiero, P. Leccese, P. Convertini et al., "New insights into Behçet's syndrome metabolic reprogramming: citrate pathway dysregulation," Mediators of Inflammation, vol. 2018, Article ID 1419352, 8 pages, 2018.

[21] H. Horai, M. Arita, S. Kanaya et al., "MassBank: a public repository for sharing mass spectral data for life sciences," Journal of Mass Spectrometry, vol. 45, no. 7, pp. 703-714, 2010.

[22] R. Aversano, F. Contaldi, M. G. Adelfi et al., "Comparative metabolite and genome analysis of tuber-bearing potato species," Phytochemistry, vol. 137, pp. 42-51, 2017.

[23] C. Chirollo, A. Vassallo, F. Dal Piaz et al., "Investigation of the persistence of penicillin $\mathrm{G}$ and dihydrostreptomycin residues in milk of lactating buffaloes (Bubalus bubalis) using ultrahigh-performance liquid chromatography and tandem mass spectrometry," Journal of Agricultural and Food Chemistry, vol. 66, no. 25, pp. 6388-6393, 2018.

[24] C. I. G. Tuberoso, G. Serreli, F. Congiu, P. Montoro, and M. A. Fenu, "Characterization, phenolic profile, nitrogen compounds and antioxidant activity of Carignano wines," Journal of Food Composition and Analysis, vol. 58, pp. 60-68, 2017.

[25] C. I. G. Tuberoso, G. Serreli, P. Montoro, G. D'Urso, F. Congiu, and A. Kowalczyk, "Biogenic amines and other polar compounds in long aged oxidized Vernaccia di Oristano white wines," Food Research International, vol. 111, pp. 97-103, 2018.

[26] A. Gambuti, D. Strollo, M. Ugliano, L. Lecce, and L. Moio, "trans-Resveratrol, quercetin, (+)-catechin, and (-)-epicatechin content in south Italian monovarietal wines: relationship with maceration time and marc pressing during winemaking," Journal of Agricultural and Food Chemistry, vol. 52, no. 18, pp. 5747-5751, 2004.

[27] R. Medzhitov, "Inflammation 2010: new adventures of an old flame," Cell, vol. 140, no. 6, pp. 771-776, 2010.

[28] P. Convertini, V. Infantino, F. Bisaccia, F. Palmieri, and V. Iacobazzi, "Role of FOXA and Sp1 in mitochondrial acylcarnitine carrier gene expression in different cell lines," Biochemical and Biophysical Research Communications, vol. 404, no. 1, pp. 376-381, 2011.

[29] V. Infantino, V. Iacobazzi, F. D. Santis, M. Mastrapasqua, and F. Palmieri, "Transcription of the mitochondrial citrate carrier gene: role of SREBP-1, upregulation by insulin and downregulation by PUFA," Biochemical and Biophysical Research Communications, vol. 356, no. 1, pp. 249-254, 2007.

[30] A. Santarsiero, A. Onzo, R. Pascale et al., "Pistacia lentiscus Hydrosol: Untargeted Metabolomic Analysis and AntiInflammatory Activity Mediated by NF- $\kappa \mathrm{B}$ and the Citrate Pathway," Oxidative Medicine and Cellular Longevity, vol. 2020, Article ID 4264815, 14 pages, 2020.

[31] T. C. Linn and P. A. Srere, "Identification of ATP citrate lyase as a phosphoprotein.," The Journal of Biological Chemistry, vol. 254, no. 5, pp. 1691-1698, 1979.

[32] T. Migita, T. Narita, K. Nomura et al., "ATP citrate lyase: activation and therapeutic implications in non-small cell lung cancer," Cancer Research, vol. 68, no. 20, pp. 8547-8554, 2008.

[33] A. Vassallo, V. Santoro, I. Pappalardo et al., "Liposome-mediated inhibition of inflammation by hydroxycitrate," Nanomaterials (Basel), vol. 10, no. 10, p. 2080, 2020.
[34] S. Suriano, L. Tarricone, M. Savino, and M. R. Rossi, "Caratterizzazione fenolica di Uve di Aglianico e Uva di Troia coltivate nel nord barese," Enologo Milano, vol. 41, p. 71, 2005.

[35] E. Celotti, R. Ferrarini, R. Zironi, and L. S. Conte, "Resveratrol content of some wines obtained from dried Valpolicella grapes: Recioto and Amarone," Journal of Chromatography A, vol. 730, no. 1-2, pp. 47-52, 1996.

[36] F. Galgano, M. Caruso, G. Perretti, and F. Favati, "Authentication of Italian red wines on the basis of the polyphenols and biogenic amines," European Food Research and Technology, vol. 232, no. 5, pp. 889-897, 2011.

[37] R. Medzhitov, "Origin and physiological roles of inflammation," Nature, vol. 454, no. 7203, pp. 428-435, 2008.

[38] S. Ghosh and M. S. Hayden, "New regulators of NF- $\kappa$ B in inflammation," Nature Reviews. Immunology, vol. 8, no. 11, pp. 837-848, 2008.

[39] C. Di Lorenzo, C. Stockley, F. Colombo et al., "The role of wine in modulating inflammatory processes: a review," Beverages, vol. 4, no. 4, p. 88, 2018.

[40] N. C. Williams and L. A. O’Neill, “ACLY-matizing macrophages to histone modification during immunometabolic reprogramming," Trends in Immunology, vol. 41, no. 2, pp. 93-94, 2020.

[41] M. A. Lauterbach, J. E. Hanke, M. Serefidou et al., "Toll-like receptor signaling rewires macrophage metabolism and promotes histone acetylation via ATP-citrate lyase," Immunity, vol. 51, no. 6, pp. 997-1011.e7, 2019.

[42] M. G. Daskalaki, C. Tsatsanis, and S. C. Kampranis, "Histone methylation and acetylation in macrophages as a mechanism for regulation of inflammatory responses," Journal of Cellular Physiology, vol. 233, no. 9, pp. 6495-6507, 2018.

[43] S. Todisco, P. Convertini, V. Iacobazzi, and V. Infantino, "TCA cycle rewiring as emerging metabolic signature of hepatocellular carcinoma," Cancers (Basel), vol. 12, no. 1, p. 68, 2020.

[44] F. Aktan, "iNOS-mediated nitric oxide production and its regulation," Life Sciences, vol. 75, no. 6, pp. 639-653, 2004.

[45] J. Anrather, G. Racchumi, and C. Iadecola, "NF- $\kappa$ B regulates phagocytic NADPH oxidase by inducing the expression of gp91," The Journal of Biological Chemistry, vol. 281, no. 9, pp. 5657-5667, 2006.

[46] A. Decendit, M. Mamani-Matsuda, V. Aumont et al., "Malvidin-3-O- $\beta$ glucoside, major grape anthocyanin, inhibits human macrophage- derived inflammatory mediators and decreases clinical scores in arthritic rats," Biochemical Pharmacology, vol. 86, no. 10, pp. 1461-1467, 2013.

[47] I. Kekelidze, N. Ebelashvili, M. Japaridze, B. Chankvetadze, and L. Chankvetadze, "Phenolic antioxidants in red dessert wine produced with innovative technology," Annals of Agrarian Science, vol. 16, no. 1, pp. 34-38, 2018.

[48] M. M. Ma, Y. Li, X. Y. Liu et al., "Cyanidin-3-O-glucoside ameliorates lipopolysaccharide-induced injury both in vivo and in vitro suppression of NF- $\kappa \mathrm{B}$ and MAPK pathways," Inflammation, vol. 38, no. 4, pp. 1669-1682, 2015.

[49] M. M. Poulsen, K. Fjeldborg, M. J. Ornstrup, T. N. Kjær, M. K. Nøhr, and S. B. Pedersen, "Resveratrol and inflammation: challenges in translating pre-clinical findings to improved patient outcomes," Biochimica et Biophysica Acta, vol. 1852, no. 6, pp. 1124-1136, 2015.

[50] G. J. Soleas, D. M. Goldberg, E. Ng, A. Karumanchiri, E. Tsang, and E. P. Diamandis, "Comparative evaluation of four 
methods for assay of cis- and trans-resveratrol," American Journal of Enology and Viticulture, vol. 48, pp. 169-176, 1997.

[51] G. Schett and M. F. Neurath, "Resolution of chronic inflammatory disease: universal and tissue-specific concepts," Nature Communications, vol. 9, no. 1, p. 3261, 2018.

[52] T. Magrone and E. Jirillo, "Polyphenols from red wine are potent modulators of innate and adaptive immune responsiveness," The Proceedings of the Nutrition Society, vol. 69, no. 3, pp. 279-285, 2010.

[53] B. J. von Scholten, H. Reinhard, T. W. Hansen et al., "Markers of inflammation and endothelial dysfunction are associated with incident cardiovascular disease, all-cause mortality, and progression of coronary calcification in type 2 diabetic patients with microalbuminuria," Journal of Diabetes and its Complications, vol. 30, no. 2, pp. 248-255, 2016.

[54] R. Otton, A. P. Bolin, L. T. Ferreira, M. P. Marinovic, A. L. S. Rocha, and M. A. Mori, "Polyphenol-rich green tea extract improves adipose tissue metabolism by down- regulating miR-335 expression and mitigating insulin resistance and inflammation," The Journal of Nutritional Biochemistry, vol. 57, pp. 170-179, 2018.

[55] M. A. Potenza, D. Iacobazzi, L. Sgarra, and M. Montagnani, "The intrinsic virtues of EGCG, an extremely good cell guardian, on prevention and treatment of diabesity complications," Molecules, vol. 25, no. 13, p. 3061, 2020.

[56] M. Z. Fang, Y. Wang, N. Ai et al., “Tea polyphenol (-)-epigallocatechin-3-gallate inhibits DNA methyltransferase and reactivates methylation-silenced genes in cancer cell lines," Cancer Research, vol. 63, no. 22, pp. 7563-7570, 2003.

[57] Q. Meng, C. N. Velalar, and R. Ruan, "Regulating the agerelated oxidative damage, mitochondrial integrity, and antioxidative enzyme activity in Fischer 344 rats by supplementation of the antioxidant epigallocatechin-3-gallate," Rejuvenation Research, vol. 11, no. 3, pp. 649-660, 2008. 